\title{
Use of orthogonal arrays and design of experiment via Taguchi L9 method in probability of default
}

\author{
Amir Ahmad Dar ${ }^{a *}$ and N. Anuradhab
}

${ }^{a}$ Department of Mathematics and Actuarial Science, B s Abdur Rahman University Chennai india-48

${ }^{b}$ Department of Management Studies, B S Abdur Rahman university Chennai india- 48

C H R O N I C L E A B S T R A C T

Article history:

Received August 17, 2017

Received in revised format

September 112017

Accepted November 12017

Available online

November 12017

Keywords:

$P D$

$B S M$

Taguchi method

Regression line

ANOM

ANOVA
The Taguchi's orthogonal array is based on a mathematical model of factorial designs. This paper investigates the effects of four parameters in Probability of Default (PD) using BlackScholes model (BSM) for call option at one period by considering asset value $V$, firm's debt $X$, expected growth $r$ and the volatility $\sigma$. The main aim is to determine which parameters affect mostly on PD of a firm. The experiment is based on the orthogonal array L9 in which the four parameters are varied at three levels. Finally, the ANOM is used to describe the best combination and ANOVA is implemented to measure the contribution of the given independent variables.

\section{Introduction}

Design of experiment (DOE) is a statistical tool developed by R.A Fisher (England 1920's) in order to study the effect of multiple variables simultaneously. In his early experiment, he wanted to estimate how much sun-light, fertilizers, water etc. are required to produce the good crop. There are two main approaches to DOE, Full Factorial design (FFD) and the Taguchi's method. The FFD is a set of an experiment whose design consists of more than one factor each with discrete possible level and whose experiment units takes all possible combinations of all those levels across all such factors. For example, if there are $K$ factors each at 3 levels, FFD has $4^{\mathrm{K}}$ runs. This for 4 factors at 3 levels it would take 81 trials runs. The Taguchi method is a statistical tool developed by Genier Taguchi (1940's) a Japanese engineer, proposed a model for experiment design. The Taguchi experiment array design is used to arrange the parameters affecting the process and the levels of which they should be varied. Instead of having all possible experiments like FFD, Taguchi model provides a minimum number of experiments. In case of 4 factors and 3 levels, it would take 9 trials runs. The experiments are not randomly generated

* Corresponding author

E-mail address: sagaramir200@gmail.com (A. A. Dar) 
but they are based on judgmental sampling. It reduces time, resources and cost. The Taguchi experimental array design is used to arrange the parameters affecting the process and the levels of which they should be varied.

In this report, we design the experiment on PD with the help of BSM. The main aim of this paper is to do an experiment on PD in order to measure which parameter affects more on the probability of default. To design an experiment author's need a data that is given in section 1.2 and the following steps that are necessary for doing the experiment.

\section{Selection of predictors $(\mathrm{V}, \mathrm{K}, \mathrm{r}$ and $\sigma)$}

2. Selection of the number of levels for each predictor (3 levels)

\section{Selection of the orthogonal array}

4. The result of response variables based on predictors assign to each column to estimate the value of a PD based on the predictors in all combinations

5. Conduct the experiment and analyse the data (applying ANOM and ANOVA to get results.

The ANOM and ANOVA are used to conduct the analysis to decide which independent variable does not have much effect (or which one effects more on option pricing formula) and also the percentage contributions of the independent variables.

\subsection{Literature review}

Now-a-days many engineers are using Taguchi's orthogonal array to design the experiment (Taguchi, 1986). It is used in every field such as Education, Engineering, physics, chemistry, Environmental science, etc. Many researchers used Taguchi method to do research on the permanent magnet. The permanent magnet is characterised by high remanence, energy product and coercivity. These are the parameters that affect the magnetic property (Besenicar \& Drofenick, 1991; Thompson \& Evans, 1990; Tanasoiu et al., 1976; Çiçek et al., 2012). Chan et al. (2014) investigated the effect of four parameters; catalyst loading, type of catalyst, reaction temperature and the nitrogen gas on liquid yield (bio-oil). The catalyst loading affects more on liquid yield than others. Shravani et al. (2011) used the Taguchi L9 orthogonal array design to measure the optimised formulation of duloxetine hydrochloride. Rodrigues et al. (2012) used the Taguchi's approach in order to measure the effects of feed cut, speed and the depth of the cut on roughness and cutting force in turning mild steel using high speed steel cutting tool. Taguchi orthogonal array measures that the cutting speed had a significant effect on surface roughness and the feed rate and cut rate had a significant effect on roundness error. The factors that affect on metal removal rate (MMR) are voltage, electrolyte concentration and feed rate. The feed rate affects more on MMR approximately $59 \%$ by using the Taguchi L9 orthogonal array (Rama \& Padmanabhan, 2012).

Therefore, the aim of the paper to find which parameter affects more on the PD with the help of a statistical tool Taguchi L9 orthogonal array, ANOM and ANOVA.

\subsection{Research Methodology}

The purpose of this study is to do experiment on PD at three levels using Taguchi orthogonal array method (3 levels and 4 parameters means that Authors have to do 9 experiments instead of 81). Finally, the authors implement ANOM and ANOVA to describe the various properties. The author's used a data shown in Table 1 (Amir \& Anuradha, 2017). 
Table 1

A data set showing the necessary information for call option

\begin{tabular}{lcccc}
\hline & \multicolumn{4}{c}{ Parameters } \\
\cline { 2 - 5 } Levels & $\mathrm{V}$ & $X$ & $r$ & $\sigma$ \\
\hline 1 & 130 & 100 & $5 \%$ & $20 \%$ \\
2 & 140 & 105 & $7 \%$ & $30 \%$ \\
3 & 150 & 118 & $9 \%$ & $40 \%$ \\
\hline
\end{tabular}

The parameters shown in Table 1 are sufficient to measure the PD of a firm using BSM-European call option.

\subsection{Objectives}

As per literary review, we have found that the researchers have so far worked on option pricing model using Taguchi's orthogonal array design whereas Taguchi's model (L9) can be used in option pricing too. The objectives of this study are:

- To measures which factors are more important than others,

- To measure the percentage contribution of each parameter,

- To check that whether there is any mean differences between the parameters.

\section{Probability of default}

The BSM was first used by Merton (1974) who applies the option pricing formula of Black Scholes model to find the firms default. According to Merton model, the capital structure of a firm is assumed to be collected by Zero coupon bond and equity with expiry time $T$ and the face value of $X$.

The Merton model for credit risk has three steps:

1. Use the BSM formula for call option to find the price or value of the firm's equity.

2. Using the firm's equity value authors will assume that the firms asset value and asset volatility, estimate the probability default (PD).

3. The authors are going to assume that the firm's asset price follows lognormal distribution.

Role of BSM for European Call option in Merton for credit risk:

The Black-Scholes for a European call option

$$
C(V, T)=V * N\left(d_{1}\right)-X * e^{-r T} N\left(d_{2}\right)
$$

where

$$
\begin{aligned}
& \mathrm{d}_{1}=\frac{\ln \left(\frac{\mathrm{V}}{\mathrm{X}}\right)+\left(\mathrm{r}+\frac{\sigma^{2}}{2}\right) \mathrm{T}}{\sigma \sqrt{\mathrm{T}}} \\
& \mathrm{d}_{2}=\frac{\ln \left(\frac{\mathrm{V}}{\mathrm{X}}\right)+\left(\mathrm{r}-\frac{\sigma^{2}}{2}\right) \mathrm{T}}{\sigma \sqrt{\mathrm{T}}}=\mathrm{d}_{1}-\sigma \sqrt{\mathrm{T}}
\end{aligned}
$$

In order to estimate the PD of a firm the authors assume that:

1. $\mathrm{S}$ in BSM is replaced by firm asset value, $\mathrm{V}$ in Merton model, where $\mathrm{V}=\mathrm{D}+\mathrm{E}$ 
2. $\mathrm{K}$ in BSM is replaced by firm's debt $\mathrm{X}$ in Merton model, its total face value of debt because that is the "strike" that must be paid to retire debt and own the firm's assets.

3. $\mathrm{r}$ is the expected growth on the firm's asset not risk free rate.

Firm's value (V) corresponds to stock price (S), Firm's value debt (X) corresponds to exercise/strike price $(\mathrm{K})$ and $r$ is the expected growth on the firm's asset not risk free rate. The PD formula is:

$$
\mathrm{N}\left(-\mathrm{d}_{2}\right)=\mathrm{N}\left(-\frac{\ln \left(\frac{\mathrm{V}}{\mathrm{X}}\right)+\left(\mathrm{r}-\frac{\sigma^{2}}{2}\right) \mathrm{T}}{\sigma \sqrt{\mathrm{T}}}\right)
$$

The values of PD in all three levels using Eq. (4) are shown in Table 2.

Table 2

PD of a firm

\begin{tabular}{lccccc}
\hline S. No. & V & X & r & Volatility $\sigma$ & PD \\
\hline 1 & 130 & 100 & $5 \%$ & $20 \%$ & 0.071895 \\
2 & 140 & 105 & $7 \%$ & $30 \%$ & 0.045666 \\
3 & 150 & 118 & $9 \%$ & $40 \%$ & 0.0606 \\
\hline
\end{tabular}

\section{Design of Experiment (DOE) using Taguchi orthogonal array}

After all the experiments according to Taguchi's method, the Analysis of mean (ANOM) is used to decide the optimal level (Phadke, 1989; Peace, 1993). The advantage of Taguchi method is to minimise the number of experiments. This would have an effect that substitutes the full factorial design of an experiment. As per the data, the four parameters and three levels as shown in Table 1. The minimum orthogonal array is selected as per Taguchi method that is $L 9\left(3^{4}\right)$. Only 9 experiments are required instead of 81 as per factorial method (where each factor is varied, one at a time, while all of the other factors remain constant) shown in Table 3.

\section{Table 3}

Taguchi experiments

\begin{tabular}{llllll}
\hline Experiments & A & B & C & D & Experiment result \\
\hline 1 & 1 & 1 & 1 & 1 & $\beta 1$ \\
2 & 1 & 2 & 2 & 2 & $\beta 2$ \\
3 & 1 & 3 & 3 & 3 & $\beta 3$ \\
4 & 2 & 1 & 2 & 3 & $\beta 4$ \\
5 & 2 & 2 & 3 & 1 & $\beta 5$ \\
6 & 2 & 3 & 1 & 2 & $\beta 6$ \\
7 & 3 & 1 & 3 & 2 & $\beta 7$ \\
8 & 3 & 2 & 1 & 3 & $\beta 8$ \\
9 & 3 & 3 & 2 & 1 & $\beta 9$ \\
\hline
\end{tabular}

In Table 3 , the elements from $\beta 1$ to $\beta 9$ in the row are obtained by some calculations or experiments. In other words $\mathrm{A}, \mathrm{B}, \mathrm{C}$ and $\mathrm{D}$ are the independent variables and $\beta 1$ to $\beta 9$ are the dependent variables.

The ANOM is guided with these values. Take into consideration the first level of independent variable/ design variable $\mathrm{A}(\mathrm{A} 1)$, the main effect of $\mathrm{A} 1$ (MA1) is estimated as:

$$
M A 1=m A 1-m \quad m A 1=(\beta 1+\beta 2+\beta 3) / 3 \quad m=\frac{1}{9} \sum_{j=1}^{9} \beta j
$$


where $m$ is the overall mean and $\mathrm{mA} 1$ is the average or mean of the features where the effect $\mathrm{A} 1$ is inserted. The average of all variables or corresponding features to each and every level for design variables is shown in Table 4. The optimal level of each and every variable is the level with minimum mean. This process is called Analysis of mean (ANOM).

\section{Table 4}

Mean of $\beta$ (result) corresponding to each level

\begin{tabular}{llccc}
\hline \multicolumn{5}{c}{ Parameters } \\
\hline Level & $\mathrm{A}$ & $\mathrm{B}$ & $\mathrm{C}$ & $\mathrm{D}$ \\
\hline 1 & $\mathrm{~mA} 1=(\beta 1+\beta 2+\beta 3) / 3$ & $\mathrm{mB} 1=(\beta 1+\beta 4+\beta 7) / 3$ & $\mathrm{mC} 1=(\beta 1+\beta 6+\beta 8) / 3$ & $\mathrm{mD} 1=(\beta 1+\beta 5+\beta 9) / 3$ \\
2 & $\mathrm{~mA} 2=(\beta 4+\beta 5+\beta 6) / 3$ & $\mathrm{mB} 2=(\beta 2+\beta 5+\beta 8) / 3$ & $\mathrm{mC} 2=(\beta 2+\beta 4+\beta 9) / 3$ & $\mathrm{mD} 2=(\beta 2+\beta 6+\beta 7) / 3$ \\
3 & $\mathrm{~mA} 3=(\beta 7+\beta 8+\beta 9) / 3$ & $\mathrm{mB} 3=(\beta 3+\beta 6+\beta 9) / 3$ & $\mathrm{mC} 3=(\beta 3+\beta 5+\beta 7) / 3$ & $\mathrm{mD} 3=(\beta 3+\beta 4+\beta 8) / 3$ \\
\hline
\end{tabular}

\section{Result, Analysis and Discussion}

The following summarizes the results of the regression analysis

$$
\begin{aligned}
& \mathrm{PD}=-0.130-0.005543 \mathrm{~V}+0.007432 \mathrm{X}-0.496 \mathrm{r}+1.0444 \text { Volatility }(\sigma) \\
& \mathrm{S}=0.0170030 \mathrm{R}^{2}=0.9899 \text { Adjusted } \mathrm{R}^{2}=0.9798 \text { Predicted } \mathrm{R}^{2}=0.9450
\end{aligned}
$$

The R-sq in the model is equal to $98.99 \%$ of the variation in the response variable, which indicates that the model provides an enough fit to the data.

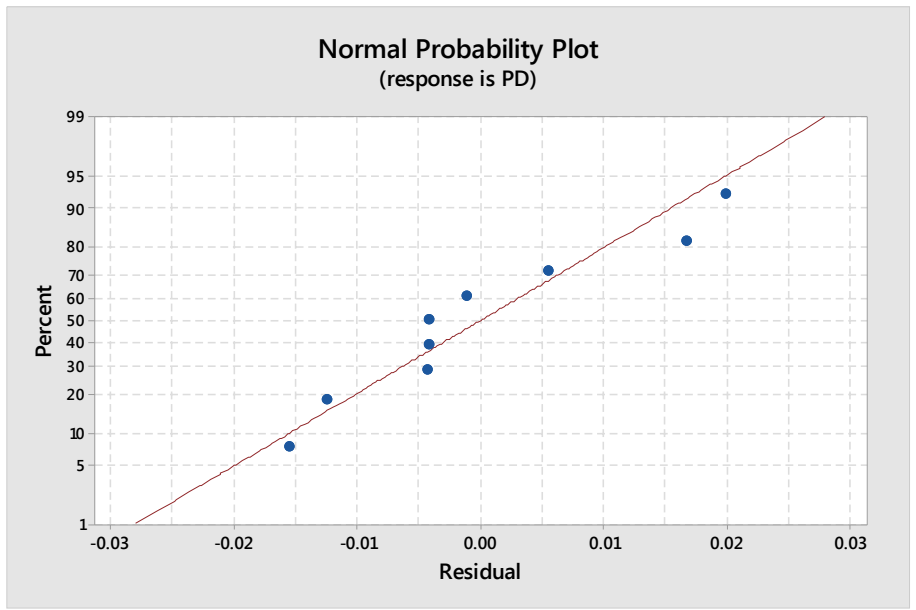

Fig. 1. Normal probability plot

The normal probability graph of the residuals is used in order to verify the assumption that it follows the normal distribution. The probabilities of default values are approximately follow a straight line.

The patterns in the following table may indicate that the model does not meet the model assumptions.

\begin{tabular}{ll}
\hline Pattern & Pattern indicates \\
\hline Not a straight line & Non-Normality \\
A point far from the line & Outlier \\
Slope changing & Undefined variable \\
\hline
\end{tabular}

According to Fig. 1, the values of the probability of default approximately follow a straight line at $95 \%$ confidence interval, which indicates that there is no evidence of non-normality, outlier or undefined variable. 
In this paper the authors are working PD of a firm using the parameters $\mathrm{V}, \mathrm{X}, \mathrm{r}$ and $\sigma$ instead of $\mathrm{A}, \mathrm{B}$, $\mathrm{C}$ and $\mathrm{D}$. Table 5 shows all combinations that are required according to Taguchi's model and the result is the value of PD using the Eq. (4).

\section{Table 5}

Taguchi's model for PD estimation

\begin{tabular}{lccccc}
\hline Exp. No. & $\mathrm{V}$ & $\mathrm{X}$ & $\mathrm{r}$ & Volatility $(\sigma)$ & $\mathrm{PD}$ \\
\hline 1 & 130 & 100 & $5 \%$ & $20 \%$ & 0.071895 \\
2 & 130 & 105 & $7 \%$ & $30 \%$ & 0.213235 \\
3 & 130 & 118 & $9 \%$ & $40 \%$ & 0.394687 \\
4 & 140 & 100 & $7 \%$ & $40 \%$ & 0.207198 \\
5 & 140 & 105 & $9 \%$ & $20 \%$ & 0.036855 \\
6 & 140 & 118 & $5 \%$ & $30 \%$ & 0.278761 \\
7 & 150 & 100 & $9 \%$ & $30 \%$ & 0.066607 \\
8 & 150 & 105 & $5 \%$ & $40 \%$ & 0.207054 \\
9 & 150 & 118 & $7 \%$ & $20 \%$ & 0.073564 \\
\hline
\end{tabular}

\subsection{Analysis of Mean (ANOM)}

ANOM is a graphical analog to ANOVA. It experiments the equality of sample means. The main aim of the ANOM is to test the effects from a designed of experiment in which all the parameters are fixed (Nelson, 1974). The null hypothesis for ANOM and ANOVA are the same, the null hypothesis is: $\mathrm{H} 0=$ there is no significant difference between the means and the alternative hypothesis is: $\mathrm{H} 1=$ there is a significant between one of the samples mean from other means. For most cases, both the statistical methods ANOVA and ANOM will give same results.

There are some outlines where both statistical methods ANOM and ANOVA differ from each other that are:

- Suppose that the mean of the 1 st group is greater than the grand mean and the 2 nd groups mean is less than the grand mean, then $F$ test gives the decision about the evidence for difference where ANOM might not.

- Suppose that the mean of the 1st group is quite different from the 2 nd group, then that time the ANOVA or F test might not give any decision about the differences of the means whereas ANOM indicates the evidence that the group is different from grand me. For more details see Ott (1983), Ott et al. (2005), Ramig (1983) and Schilling (1973). ANOM is used if the authors suppose that the independent variable follows a distribution that is the normal distribution as similar to ANOVA. ANOVA can design for two-way or one-way. The authors can also use ANOM when the response variable follows Binominal distribution or Poisson distribution. From Taguchi's orthogonal array L9 the authors used Table 4 in order to calculate the ANOM for all parameters. Table 6 is simple shows the ANOM for all the parameters.

Table 6

ANOM: Response table for mean

\begin{tabular}{lllll}
\hline Level & $\mathrm{V}$ & $\mathrm{X}$ & $\mathrm{r}$ & Volatility \\
\hline 1 & 0.226606 & $\mathbf{0 . 1 1 5 2 3 3}$ & 0.185903 & $\mathbf{0 . 0 6 0 7 7 1}$ \\
2 & 0.174271 & 0.152381 & $\mathbf{0 . 1 6 4 6 6 6}$ & 0.186201 \\
3 & $\mathbf{0 . 1 1 5 7 4 1}$ & 0.249004 & 0.166049 & 0.269646 \\
\hline Range & 0.110865 & 0.133771 & 0.021237 & 0.208875 \\
Rank & 3 & 2 & 4 & 1 \\
\hline
\end{tabular}

Range $=$ max. - Min 


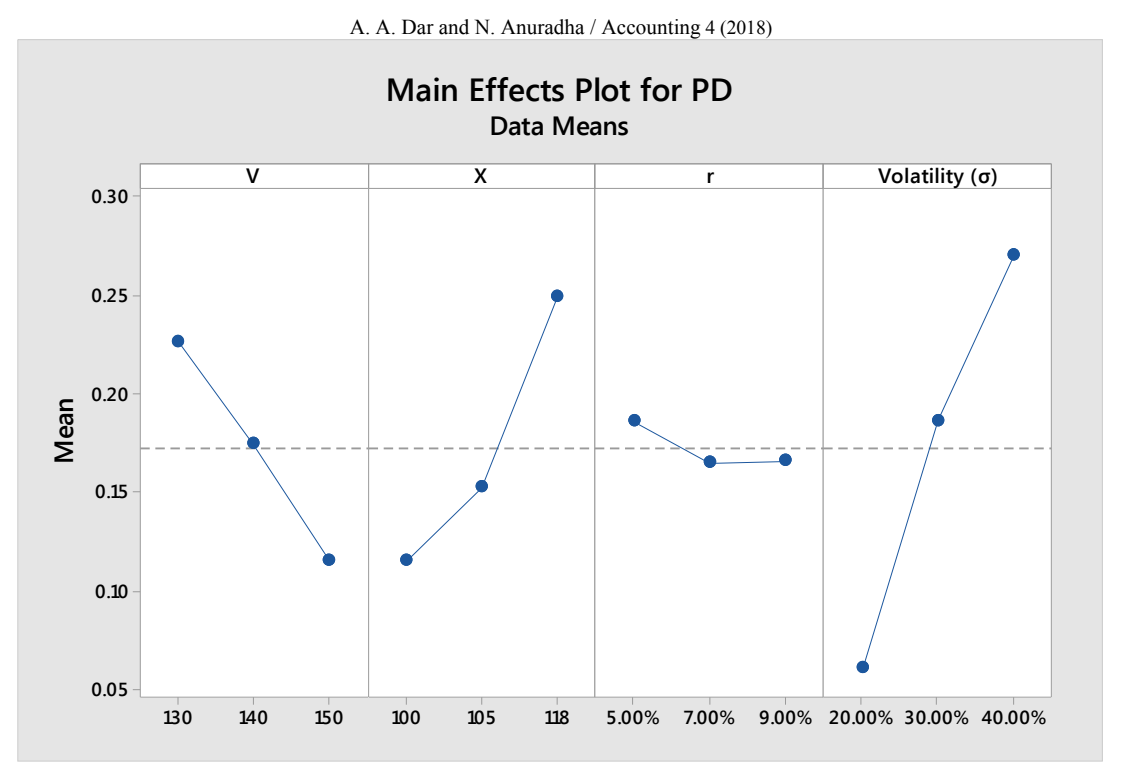

Fig. 2. Main effects plot for mean of 4 parameters

The selected numbers (bold) are the minimum in every column, as per range and set the ranking for all the parameters. The authors conclude that the best combination is $\boldsymbol{V} \mathbf{3} * \boldsymbol{X} \mathbf{1} * \boldsymbol{r} \mathbf{2} * \boldsymbol{\sigma} \mathbf{1}$ because the low $\mathrm{PD}$ is the best that is why the authors choose the ranking from low to high.

\subsection{Analysis of Variance (ANOVA)}

In order to investigate the relationship between a responsible variable and predictor variables, the authors use a regression model known as ANOVA. In the above Taguchi's orthogonal array experiment the authors are using ANOVA to measure the contribution of each parameter. The table 7 shows the contribution of each parameter.

Table 7

Contribution of each parameter

\begin{tabular}{lrrl}
\hline Parameters & Adj SS & Percentage contribution & Rank \\
\hline V & 0.018436 & $16.5625 \%$ & 3 \\
X & 0.026842 & $24.1142 \%$ & 2 \\
R & 0.000591 & $0.5309 \%$ & 4 \\
Sigma & 0.065443 & $58.7924 \%$ & 1 \\
& 0.111312 & & \\
\hline
\end{tabular}

The percentage contribution of the parameters that is shown in table 7 can be calculated as

$$
\% \text { contribution }=\frac{\text { sum of square of a parameter }}{\text { total sum of squares }}
$$

According to Fig. 3, the lines are not parallel to each other. It indicates that there is a certain relationship between the variables on PD. The percentage of each parameter is defined as the significance rate of the process parameters on the value of PD. The percent $\%$ numbers represent that the asset value of a firm V, firm's debt X, expected growth $\mathrm{r}$ and the volatility $\sigma$ at one period significantly effect on PD of a firm. It can be observed in Table 7 that the asset value V, firm's debt X, expected growth $r$ and the volatility $\sigma$ at time $t=1$, affects PD of a firm by $16.5625 \%, 24.1142 \%, 0.5309 \%$ and $58.7924 \%$ respectively. 


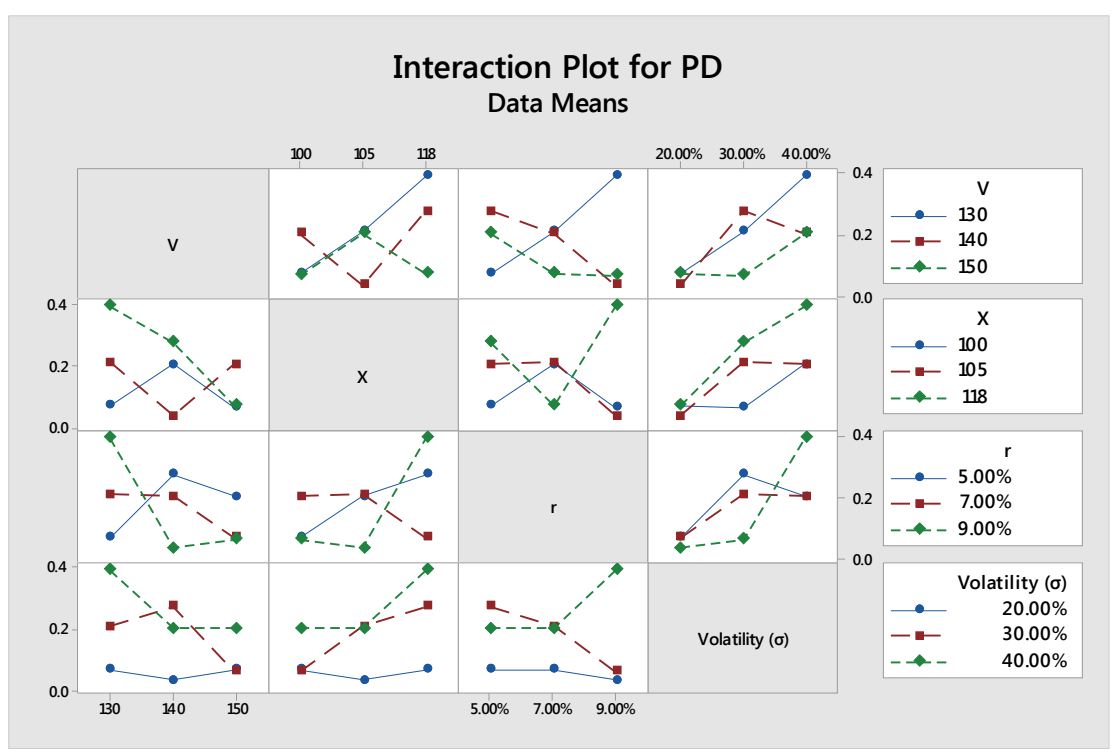

Fig. 3. Interaction plot for PD

The mean value of $\mathrm{PD}$ for each parameter is calculated in Table 6. In order to determine whether there is any mean differences between the parameters of PD (ANOM data) we need the ANOVA table that are shown in Table 8.

\section{Table 8}

ANOVA test

\begin{tabular}{lrrrrr}
\hline Source & DF & Adj SS & Adj MS & F-Value & P-Value \\
\hline Factor & 3 & 0.000000 & 0.000000 & 0.00 & 1.000 \\
Error & 8 & 0.038079 & 0.004760 & & \\
\hline Total & 11 & 0.038079 & & & \\
\hline
\end{tabular}

In ANOVA test, the null hypothesis states that there is mean difference between the 4 factors. Because the p-value is greater than 0.05 , so it concludes that we can accept the null hypothesis and the pairs have the same mean.

\section{Conclusion}

This study discussed to estimate the PD of a firm by using the BSM for call option and an application of Taguchi orthogonal array method for carrying out the effects of process parameters on the value of a PD. From the analysis of result using conceptual like Taguchi method, analysis of mean (ANOM) and the analysis of variance (ANOVA), the following results are:

- The Taguchi orthogonal array was performed to design an experiment using the L9 orthogonal array. For four parameters and three levels as per factorial method, there are $3^{\wedge} 4=81$ possibilities. However, in Taguchi L9 orthogonal array, there are only 9 possibilities. It reduces time and cost.

- The values of PD follow a normal distribution at $95 \%$ confidence interval.

- The ANOM gave an idea that which combination is giving the minimum PD. An investor must choose the $\mathrm{V} 3 * \mathrm{X} 1 * \mathrm{r} 2 * \sigma 1$ combination because it gives the less PD. With the help of Taguchi method, an investor can use it and estimate the better combination so that he/she will prevent the future loss. 
- The ANOVA showed the result at 95\% confidence interval the parameters $\mathrm{V}, \mathrm{X}, \mathrm{r}$ and $\sigma$ affect the PD of a firm by $16.5625 \%, 24.1142 \%, 0.5309 \%$ and $58.7924 \%$ respectively.

- There are no mean differences between the response factors.

The two statistical methods ANOM and ANOVA show that the volatility $\sigma$ affects more and the interest rate $r$ affects less on PD.

\begin{tabular}{llll}
\hline Rank 1 & Rank 2 & Rank 3 & Rank 4 \\
\hline Volatility $\sigma$ & Firm's debt X & Value of a firm (Firm's asset ) V & Interest rate / Expected growth (r) \\
\hline
\end{tabular}

\section{Acknowledgement}

This research did not receive any specific grant from funding agencies in the public, commercial, or not-for-profit sectors. The authors also would like to thank the anonymous referees for construction comments on earlier version of this paper.

\section{References}

Besenicar, S., \& Drofenick, M. (1991). High coercivity Sr-hexaferrite. Journal of Magnetism and Magnetic Materials, 101, 307-309

Chan, Y. H., Dang, K. V., Yusup, S., Lim, M. T., Zain, A. M., \& Uemura, Y. (2014). Studies on catalytic pyrolysis of empty fruit bunch (EFB) using Taguchi's L9 Orthogonal Array. Journal of the Energy Institute, 87(3), 227-234.

Çiçek, A., Kıvak, T., \& Samtaş, G. (2012). Application of Taguchi method for surface roughness and roundness error in drilling of AISI 316 stainless steel. Strojniški vestnik-Journal of Mechanical Engineering, 58(3), 165-174.

Dar, A.A., \& Anuradha, N. (2017). Probability default in black scholes formula: A qualitative study. Journal of Business and Economic Development, 2(2), 99-106.

Nelson, L.S. (1974). Factors for the Analysis of Means. Journal of Quality Technology, 6, 175-181.

Ott, E.R. (1983). Analysis of Means's A Graphical Procedure. Journal of Quality Technology, 15(1), 10-18.

Ott, E. R., Schilling, E. G., \& Neubauer, D. V. (2005). Process quality control: troubleshooting and interpretation of data. ASQ Quality Press.

Peace, G. S. (1993). Taguchi methods: a hands-on approach. Addison Wesley Publishing Company.

Rama, R. S., \& Padmanabhan, G. (2012). Application of Taguchi methods and ANOVA in optimization of process parameters for metal removal rate in electrochemical machining of $\mathrm{Al} / 5 \% \mathrm{SiC}$ composites. International Journal of Engineering Research and Applications (IJERA), 2(3), 192197.

Ramig, P.F. (1983). Applications of the Analysis of Means. Journal of Quality Technology, 15(1), 1925.

Rodrigues, L. L. R., Kantharaj, A. N., Kantharaj, B., Freitas, W. R. C., \& Murthy, B. R. N. (2012). Effectin of cutting parameters on surface roughness and cutting force in turning mild steel. Research Journal of Recent Science, 1 (10), 19-26.

Phadke, M.S. (1989). Quality Engineering Using Robust Design. Prentice-Hall, Englewood CliMs, NJ.

Schilling, E. G. (1973). A Systematic Approach to the Analysis of Means. Journal of Quality Technology, 5, 93-108, 147-159

Shravani, D., Lakshmi, P. K., \& Balasubramaniam, J. (2011). Preparation and optimization of various parameters of enteric coated pellets using the Taguchi L9 orthogonal array design and their characterization. Acta Pharmaceutica Sinica B, 1(1), 56-63.

Taguchi, G. (1986). Orthogonal Arrays and Linear Graph. American supplier institute, Inc., Dearborn. MI. 
Tanasoiu, C., Nicolau, P., \& Miclea, C. (1976). Preparation and magnetic properties of high coercivity strontium ferrite micropowders obtained by extended wet milling. IEEE Transactions on Magnetics, 12(6), 980-982.

Thompson, G. K., \& Evans, B. J. (1990). Magnetic properties, compositions, and microstructures of high-energy product strontium hexaferrites. Journal of Applied Physics, 67(9), 4601-4603.

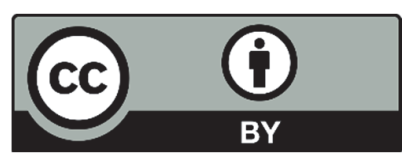

(C) 2017 by the authors; licensee Growing Science, Canada. This is an open access article distributed under the terms and conditions of the Creative Commons Attribution (CC-BY) license (http://creativecommons.org/licenses/by/4.0/). 